BMJ Surgery, Interventions, $\&$ Health Technologies

\title{
Cohort study of impact on length of stay of individual enhanced recovery after surgery protocol components
}

\author{
Rachel C. Sisodia, ${ }^{1,2}$ Dan Ellis, ${ }^{2,3}$ Michael Hidrue, ${ }^{2}$ Pamela Linov, ${ }^{2}$ Elena Cavallo, ${ }^{2}$ \\ Allison S. Bryant, ${ }^{4}$ May Wakamatsu, ${ }^{5}$ Marcela G. del Carmen (D) ${ }^{1,2}$
}

To cite: Sisodia RC, Ellis D, Hidrue M, et al. Cohort study of impact on length of stay of individual enhanced recovery after surgery protocol components. BMJ Surg Interv Health Technologies 2021;3:e000087. doi:10.1136/ bmjsit-2021-000087

Received 17 March 2021 Accepted 09 July 2021

Check for updates

(C) Author(s) (or their employer(s)) 2021. Re-use permitted under CC BY-NC. No commercial re-use. See rights and permissions. Published by BMJ.

${ }^{1}$ Division of Gynecologic Oncology, Department of Obstetrics and Gynecology,

Massachusetts General Hospital, Harvard Medical School, Boston, Massachusetts, USA

${ }^{2}$ Massachusetts General Hospital Physicians Organization,

Massachusetts General Hospital, Boston, Massachusetts, USA

${ }^{3}$ Department of Anesthesia, Critical Care \& Pain Medicine,

Massachusetts General Hospital, Harvard Medical School, Boston, Massachusetts, USA

${ }^{4}$ Division of Maternal Fetal

Medicine, Department of

Obstetrics and Gynecology,

Massachusetts General Hospital, Harvard Medical School, Boston,

Massachusetts, USA

${ }^{5}$ Division of Female Pelvic Medicine \& Reconstructive Surgery, Department of Obstetrics and Gynecology,

Massachusetts General Hospital, Harvard Medical School, Boston, Massachusetts, USA

Correspondence to

Dr Marcela G. del Carmen;

mdelcarmen@mgh.harvard.edu

\section{ABSTRACT}

Objective The goal of this study was to explore which enhanced recovery after surgery (ERAS) bundle items were most associated with decreased length of stay after surgery, most likely associated with decreased length of stay after surgery.

Design A cohort study.

Setting Large tertiary academic medical centre.

Participants The study included 1318 women undergoing hysterectomy as part of our ERAS pathway between 1 February 2018 and 30 January 2020 and a matched historical cohort of all hysterectomies performed at our institution between 3 October 2016 and 30 January 2018 $(\mathrm{n}=1063)$.

Intervention The addition of ERAS to perioperative care. This is a cohort study of all patients undergoing hysterectomy at an academic medical centre after ERAS implementation on 1 February 2018. Compliance and outcomes after ERAS roll out were monitored and managed by a centralised team. Descriptive statistics, multivariate regression, interrupted time series analysis were used as indicated.

Main outcome measures Impact of ERAS process measure adherence on length of stay.

Results After initiation of ERAS pathway, 1318 women underwent hysterectomy. There were more open surgeries after ERAS implementation, but cohorts were otherwise balanced. The impact of process measure adherence on length of stay varied based on surgical approach (minimally invasive vs open). For open surgery, compliance with intraoperative antiemetics $(-30 \%, 95 \% \mathrm{Cl}-18 \%$ to $40 \%$ ) and decreased postoperative fluid administration $(-12 \%, 95 \% \mathrm{Cl}-1 \%$ to $21 \%)$ were significantly associated with reduced length of stay. For minimally invasive surgery, ambulation within 8 hours of surgery was associated with reduced length of stay $(-53 \%, 95 \% \mathrm{Cl}-55 \%$ to $52 \%)$.

Conclusions While adherence to overall ERAS protocols decreases length of stay, the specific components of the bundle most significantly impacting this outcome remain elusive. Our data identify early ambulation, use of antiemetics and decreasing postoperative fluid administration to be associated with decreased length of stay.

\section{INTRODUCTION}

For over two decades, implementation of enhanced recovery after surgery (ERAS)

\section{Key messages}

What is already known about this subject?

- The benefits of enhanced recovery after surgery (ERAS) pathways on surgical care have been well described in the literature. However, most studies describe ERAS implementation in an intention-totreat analysis, assuming total adherence to a large bundle of interventions. Recent literature shows that institutions have marked difficulty in adherence to the bundle, particularly over time.

What are the new findings?

- Our study underscores the importance of measuring strict adherence to ERAS pathways bundle items in order to optimise programme success. It also highlights the benefit of tailoring the protocol to include only critical items that will facilitate programme implementation, adherence and sustainability.

\section{How might these results affect future} research or surgical practice?

- Our study offers a model of ERAS bundle for hysterectomy inclusive of only 10 components, underscoring the importance of strict adherence measurement to evaluate impact. This simpler model may facilitate implementation, compliance, outcomes and reduce cost of care.

protocols has been associated with improved perioperative outcomes. Studies have consistently shown earlier return of bowel function, shortened length of inpatient stay postsurgery, lower cost of care and reduced perioperative complication rates. ${ }^{1-3}$ Initially pioneered in colorectal surgery, this experience has been reproduced in hepatobiliary, orthopaedic, gynaecological and oncological surgery. ${ }^{4-12}$

Despite evidence that ERAS pathways offer superior perioperative outcomes, ubiquitous adoption of these programmes is limited. Protocols are lengthy and implementation is variable, success requiring coordination of multiple care team members across ambulatory, hospital and perioperative settings. 
Barriers to implementation include resistance to change, limited resources and funding, and high staff turnover. ${ }^{13-15}$ Implementation of lengthy protocols is difficult; dozens of care personnel have to perform exactly to specification, and failure to comply by even an individual can compromise the effort in its entirety. Recent studies have shown that centres must be compliant with more than $70 \%$ of the bundle to see the benefits. ${ }^{131617}$ Data show that even ERAS centres with demonstrated success in obtaining high compliance have difficulty sustaining high performance over time. In a retrospective audit of 10 of the highest performing ERAS hospitals in the Netherlands (compliance rates ranging of $64 \%-87 \%$ within first year after ERAS launch) at 3years after launch, compliance had dropped to $56 \%-73 \%$ overall $(\mathrm{p}<0.01)$ with particularly poor compliance with postoperative measures such as early ambulation. ${ }^{18}$

Physicians, nurses and hospital systems have fixed resources and time. Implementation science validates that reduction in real and perceived complexity improves the likelihood that an intervention will succeed. ${ }^{19} \mathrm{~A}$ better understanding of which components of the bundle are most important would enhance ERAS programmes adoption and maintenance. The goal of this study was to assess which components of the ERAS bundle are most important for reducing hospital length of stay (LOS) within a comprehensive ERAS programme involving all hysterectomies at a large academic centre. We specifically designed an ERAS bundle inclusive of components deemed to be critical in improving outcome after hysterectomy and measured adherence to each component to evaluate its impact on LOS. Patients were exposed to the 10-item ERAS bundle, with the following outcomes measured: surgical site infection, unplanned intensive care unit admission, LOS, anastomotic leak, readmission. We hypothesised that a more tailored ERAS protocol would result in increased adherence and reduce LOS.

\section{METHODS}

\section{Implementation of ERAS Pathway}

In 2017, the Massachusetts General Performance and Improvement organisation, the Department of Surgery and the Department of Obstetrics and Gynaecology launched an institution-wide ERAS pathway. Dedicated infrastructure to support this effort included a project manager, staff training (ambulatory staff, surgeons, nurses, anaesthesia, perioperative and postoperative teams), design of a real-time dashboard for assessment of performance on both processes and outcomes, quarterly reporting of individual performance and variation to all surgeons and monthly multidisciplinary workgroup meetings for each surgical procedure implementing ERAS, including nurses, anaesthesiologists, surgeons, administrators and office/perioperative area staff. Patient education kits, preoperative carbohydrate drinks and preoperative surgical washes (chlorhexidine) were packaged and delivered to surgeons' offices for distribution to patients. In addition, new surgical order sets reflecting
ERAS pathways replaced previous ones in the electronic health record (EHR) and were default choices for ERAS procedures.

Effective 1 February 2018, all hysterectomies performed at our institution were expected to be performed under the ERAS pathway. Prior to systematic implementation, only some clinicians implemented various ERAS processes at their discretion. Inclusion criteria included all elective total hysterectomies, including for non-cancer and cancer indications, and surgeries in which hysterectomy was performed concomitant to other procedures (prolapse repair or suspension, cancer staging procedures, debulking, exenteration and cosurgical procedures performed with other services). Laparoscopic and vaginal hysterectomies, as well as hysterectomies performed via laparotomy, were included. Using Current Procedural Terminology (CPT) code data, procedures were grouped into four categories for reporting and analysis: vaginal hysterectomy, laparoscopic hysterectomy, open hysterectomy (non-debulking) and open debulking. Unplanned surgeries (emergent and urgent) were excluded as well as hysterectomies performed after gravid delivery. To assess change in practice and outcomes over time for both reporting and analysis, the ERAS cohort was compared with a cohort of all previous hysterectomies (using aforementioned criteria) performed at the Massachusetts General Hospital between 2016 and 2018.

\section{Components of ERas pathway}

In order to increase compliance and facilitate reporting, the ERAS hysterectomy pathway was designed to be (1) concordant with previously published protocols and (2) consistent with other protocols across our institution. ${ }^{820-24}$ The protocol was segmented into preoperative, perioperative, and postoperative portions and was inclusive of 10 items.

\section{Preoperative phase}

Patients underwent usual preoperative screening with anaesthesiology, and, if indicated, were counselled in tobacco and alcohol cessation. Ambulatory nursing staff educated patients on the ERAS pathway and its goals including expectations (early ambulation and early removal of drains or Foley catheter, if applicable). Patients received an education packet and checklist. All patients were provided with chlorhexidine wash (Hibiclens) and instructed to use it daily starting 2 days preoperatively and the morning of procedure. Patients were also instructed to stop solid foods and opaque liquids after midnight the evening before surgery, and to initiate carbohydrate loading with carbohydrate-rich drinks ( $\geq 45 \mathrm{~g}$ of complex carbohydrate in $400 \mathrm{cc}$ of isotonic fluid, for example, $24 \mathrm{oz}$ of Clearfast or if unavailable, $20 \mathrm{oz}$ of Gatorade). Patients were instructed to consume these drinks before bedtime, the evening before surgery, and $2-4$ hours prior to surgery, and encouraged to liberally consume other clear liquids on the morning of surgery.

Patients at risk for colonic resection (all patients undergoing debulking surgery) underwent combined 
mechanical bowel prep with oral antibiotics per the American Society of Colon and Rectal Surgeon's Guidelines and the American College of Surgeons and Surgical Infection Society Guidelines. ${ }^{25} 26$

\section{Perioperative phase}

Prophylactic antibiotics and venous thromboembolic event (VTE) were administered per protocol. Unless contraindicated, oral acetaminophen (650-1000 mg, based on age and comorbidity) and celecoxib (400 mg) were administered prior to surgery. Two or more antiemetics to prevent postoperative nausea and vomiting, and multimodal analgesia were also administered. Regional anaesthesia (epidural, transversus abdominus plane block, rectus sheath block) were used in addition to general anaesthesia for open cases. The intraoperative fluid goal was a net zero fluid balance while maintaining a urine output of at least $0.2 \mathrm{mg} / \mathrm{kg} /$ hour. Patients were warmed throughout surgery. In cases inclusive of colonic resection, a wound protector was used prior to division of the colon. All open cases used a separate closing instrument tray, and gowns and gloves were changed prior to closure of the abdominal wall. The protocol did not permit routine use of nasogastric tube and abdominal drains. Foley catheters were removed prior to leaving the operating room, or for urogynaecological procedures, via backfill trial of void on postoperative day 0 or 1 .

\section{Postoperative phase}

Unless contraindicated, patients were written for clear liquids in the recovery room and subsequent full diet. All patients were written to be out of bed to chair or ambulate within 8 hours of presentation to recovery room, and all meals were to be taken out of bed. Intravenous fluids were written at $0.5 \mathrm{cc} / \mathrm{kg} /$ hour, and were discontinued as soon as possible. All patients were written for standing acetaminophen and/or non-steroidal anti-inflammatory drugs, unless contraindicated. First line opioids, if indicated, were oral oxycodone and tramadol. Intravenous opioids were only used for rescue. Patients with an epidural in place underwent a backfill trial of void at time of Foley removal on postoperative day one. If the voiding trial was unsuccessful, a Foley was replaced until the epidural was removed.

\section{Assessing Compliance with eras pathway}

In order to optimise pathway adherence and streamline reporting, our central team selected ten key ERAS process measures from various care points in the patient's surgical journey (table 1). A case was marked as compliant with that portion of the bundle if the requested criterion was met, as outlined in the ERAS bundle. Compliance data were generated from documentation and timestamps within the EHR which was pulled from the enterprise data warehouse and ultimately run through coded algorithms which assessed compliance. Failure to comply with the measure as documented in table 1, modifications to the
Table 1 Key process metrics for reporting eras pathway compliance

\begin{tabular}{|c|c|}
\hline Metric & Criteria for compliance \\
\hline \multicolumn{2}{|l|}{ Preoperative phase } \\
\hline 1. Bowel preparation & $\begin{array}{l}\text { If patient is undergoing debulking, } \\
\text { were they administered mechanical } \\
\text { bowel prep and oral antibiotics? } \\
\text { All other patients: Was no bowel } \\
\text { prep administered? }\end{array}$ \\
\hline $\begin{array}{l}\text { 2. Preoperative } \\
\text { nutrition }\end{array}$ & $\begin{array}{l}\text { Did the patient drink one of the } \\
\text { approved preoperative carbohydrate } \\
\text { drinks on the morning of surgery? }\end{array}$ \\
\hline $\begin{array}{l}\text { 3. Preoperative site } \\
\text { prep: }\end{array}$ & $\begin{array}{l}\text { Did the patient use chlorhexidine } \\
\text { wash at least once preoperatively? } \\
\text { (exclude vaginal hysterectomy) }\end{array}$ \\
\hline $\begin{array}{l}\text { 4. Preemptive non- } \\
\text { opioid analgesia }\end{array}$ & $\begin{array}{l}\text { Did the patient receive preoperative } \\
\text { acetaminophen or celecoxib? }\end{array}$ \\
\hline
\end{tabular}

\section{Perioperative phase}

\begin{tabular}{|c|c|}
\hline $\begin{array}{l}\text { 5. Intraoperative } \\
\text { antiemetics }\end{array}$ & $\begin{array}{l}\text { Did the patient receive two or more } \\
\text { antiemetics? }\end{array}$ \\
\hline $\begin{array}{l}\text { 6. Intraoperative fluid } \\
\text { management: }\end{array}$ & $\begin{array}{l}\text { Did the patient receive } \leq 4 \mathrm{~mL} / \\
\mathrm{kg} / \text { hour of crystalloid/colloid } \\
\text { intraoperatively? }\end{array}$ \\
\hline $\begin{array}{l}\text { 7. Wound protector } \\
\text { use }\end{array}$ & $\begin{array}{l}\text { If the colon was divided, was a } \\
\text { wound protector used? }\end{array}$ \\
\hline \multicolumn{2}{|l|}{ Postoperative phase } \\
\hline $\begin{array}{l}\text { 8. Postoperative } \\
\text { analgesia }\end{array}$ & $\begin{array}{l}\text { Did patient receive non- } \\
\text { opioid analgesics (Ketorolac, } \\
\text { acetaminophen, NSAIDS) at least } \\
\text { once within } 24 \text { hours? }\end{array}$ \\
\hline $\begin{array}{l}\text { 9. Postoperative fluid } \\
\text { management }\end{array}$ & $\begin{array}{l}\text { Did patients receive } \leq 1 \mathrm{mg} / \mathrm{kg} / \mathrm{hour} \\
\text { of intravenous fluids for the first } 48 \\
\text { hours postoperatively (average)? }\end{array}$ \\
\hline $\begin{array}{l}\text { 10. Early } \\
\text { postoperative } \\
\text { ambulation }\end{array}$ & $\begin{array}{l}\text { Did the nurse document that the } \\
\text { patient was out of bed to chair } \\
\text { or ambulating within } 8 \text { hours after } \\
\text { surgery? }\end{array}$ \\
\hline
\end{tabular}

NSAID, non-steroidal anti-inflammatory.

measure, and absence of documentation were all marked as non-compliant.

\section{Data collection and statistical analysis}

For the cohort of patients who had surgery after ERAS implementation (1 February 2018), key demographic variables (ex: age, body mass index, BMI, American Society of Anaesthesia, ASA class), surgical information (surgeon, type of surgery, procedures in addition to hysterectomy), compliance with ERAS pathway measures and traditional postoperative outcomes of interest (surgical site infection, unplanned intensive care unit admission, LOS, anastomotic leak, readmission) were gathered prospectively. The following BMI categories were analysed: Normal (BMI 18.5 to $<25 \mathrm{~kg} / \mathrm{m}^{2}$ ); overweight (BMI 25 to $<30 \mathrm{~kg}$ / $\mathrm{m}^{2}$ ) and obese (BMI $30 \mathrm{~kg} / \mathrm{m}^{2}$ or higher). 
For the comparative group of patients pre-ERAS intervention (3 October 2016-30 January 2018), data were retrospectively collected via coded algorithms which pulled from the enterprise data warehouse. For variables difficult to assess by coding, such as use of wound protector, additional manual chart reviews were performed by ERAS-trained personnel. Though the use of wound protector for colonic division at time of hysterectomy was recorded, only debulking with colonic resection was eligible for this metric so we removed it from the analysis.

Standard descriptive statistics were used to characterise the pre-ERAS and post-ERAS implementation samples and $\chi^{2}$ test was used to compare characteristics of patients between the two samples. Since sample size for some of the procedures was small, we group them into two categories: minimally invasive surgery (laparoscopic and vaginal) and open surgery (debulking surgery and open abdominal hysterectomy). To assess the impact of ERAS implementation on LOS, interrupted time series analysis was used to disentangle the impact of the intervention from temporal changes in LOS. Specifically, we adjusted for the ERAS intervention and secular trends. Since the distribution of patients by age group, procedure type, procedure day (weekend vs weekday) and ASA category differ between the pre-ERAS and post-ERAS implementation samples, we also controlled for these differences in the interrupted time series model. Finally, we used the Durbin-Watson d statistic to test for autocorrelation in the data.
Next, we used multivariate regression model to assess the impact of individual ERAS metrics on LOS. For this analysis, the association of compliance with ERAS process measure is assessed regardless of whether the procedure was performed before or after the ERAS initiative. Covariates included the nine process measures, type of surgery, ASA class, age, having diabetic, procedure day (weekend vs weekday) and surgery year. Because the impact of a process measure on LOS depends on type of surgery, we used separate regression for each surgery type. Finally, since distribution of LOS is skewed, we specified a generalised linear model with gamma distribution and log link. A $p<0.05$ was used to establish statistical significance and regression results are reported as rate ratio. All statistical analyses were performed using SAS V.9.4 (SAS Institute).

\section{RESULTS}

Between 1 February 2018 and 30 January 2020, 1318 women underwent hysterectomy as part of our ERAS pathway. This cohort was compared with a matched historical cohort of all hysterectomies performed at our institution between 3 October 2016 and 30 January $2018(\mathrm{n}=1063)$. The cohort after ERAS implementation included more debulking surgeries and open hysterectomies, fewer procedures on weekends and was more likely to have ASA class missing, but there were no other significant differences between the two groups (table 2).

\begin{tabular}{|c|c|c|c|}
\hline Covariate & Preimplementation $(\mathrm{N}=1063$ ) & Postimplementation ( $\mathrm{N}=1318$ ) & $P$ value \\
\hline Age group & & & 0.0500 \\
\hline$\leq 45$ years & $302(28.4)$ & $380(28.8)$ & \\
\hline $46-65$ years & $538(50.6)$ & $611(46.4)$ & \\
\hline$>65$ years & $223(21.0)$ & $327(24.8)$ & \\
\hline Procedure day & & & 0.033 \\
\hline Weekdays & $1021(96.0)$ & $1286(97.6)$ & \\
\hline Weekends & $42(4.0)$ & $32(2.4)$ & \\
\hline Procedure type & & & 0.009 \\
\hline Minimally invasive & $953(89.6)$ & $1135(86.1)$ & \\
\hline Open & $110(10.4)$ & $183(13.9)$ & \\
\hline ASA category & & & $<0.0001$ \\
\hline Healthy & $92(8.7)$ & $89(6.7)$ & \\
\hline Mild & $713(67.1)$ & $788(59.8)$ & \\
\hline Sever & $189(17.8)$ & $255(19.4)$ & \\
\hline Missing & $69(6.5)$ & $186(14.1)$ & \\
\hline BMI category & & & 0.9396 \\
\hline Normal $(18.5$ to <25) & $332(31.2)$ & $408(31.0)$ & \\
\hline Overweight $(25$ to $<30)$ & 307 (28.9) & $375(28.5)$ & \\
\hline Obese $(\geq 30)$ & $424(39.9)$ & $535(40.6)$ & \\
\hline
\end{tabular}

ASA, American Society of Anesthesia; BMI, body mass index; ERAS, enhanced recovery after surgery. 
Preop nutritional supplement $(p<0.0001)$

Preemptive Analgesia $(\mathrm{P}<0.0001)$

Bowel preparation $(p=0004)$

Preop Abx shower $(p<0.0001)$

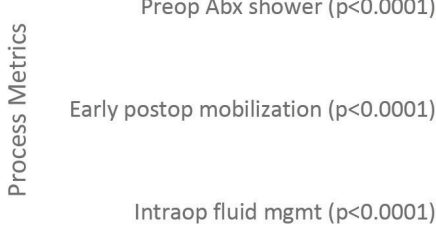

Postop fluid mgmt ( $p=0.002$ )

Postop analgesia $(p=0.3008$

Intraop med use (antiemetics) $(p=0.263$
3.4

53.9

43

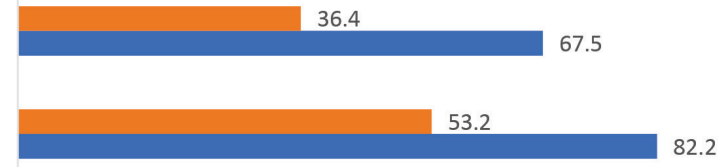

82.2

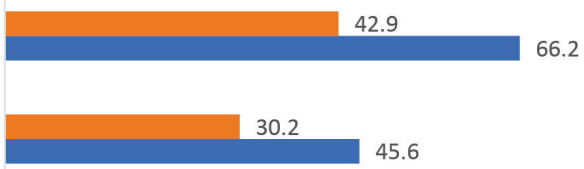

27

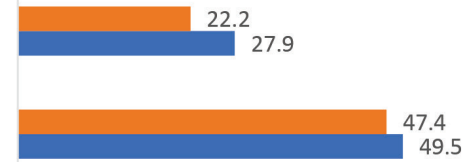

9.5

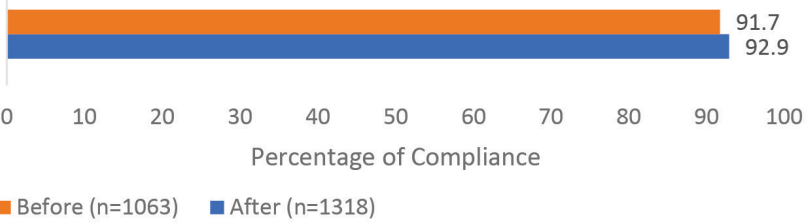

Figure 1 Compliancewith key surgical process metrics, before and after ERAS implementation. ERAS, enhanced recovery after surgery.

\section{Assessing the impact of the eras initiative on Compliance}

Figure 1 shows how implementation of ERAS impacted key process metrics overall. The improvements, from the highest to the lowest, were as follows: consumption of a preoperative nutritional supplement/carbohydrate drink $(+50.5, \mathrm{p}<0.001 \%)$, administration of preoperative non-opioid analgesia $(+41.5 \%, \mathrm{p}<0.001)$, bowel preparation for appropriate patients $(+31.1 \%, \mathrm{p}<0.001)$, preop chlorhexidine wash $(+29 \%, \mathrm{p}<0.001)$, early postoperative mobilisation $(+23.3 \%, \mathrm{p}<0.001)$, intraop $<4 \mathrm{cc} / \mathrm{kg} /$ hour $(+15.4 \%, \mathrm{p}<0.001)$, postoperative fluids at a rate $<1$ $\mathrm{cc} / \mathrm{kg} /$ hour $(+5.7 \%, \mathrm{p}=0.002)$, postoperative analgesia $(+2.1 \%, \mathrm{p}=0.301)$ and antiemetics $(+1.2 \%, \mathrm{p}=0.263)$.

Compliance rates and LOS per process measure differed by surgical approach. For minimally invasive procedures, compliance rate with preemptive analgesia and postoperative analgesia was $65.8 \%$ and $41.3 \%$, respectively. In this group, compliance with intraoperative and postoperative fluid management was $41.3 \%$ and $20.9 \%$, respectively. Adherence to preoperative carbohydrate load and use of preoperative Hibiclens occurred in $30.1 \%$ and $68.8 \%$ of these cases, respectively. Protocol-defined used of antiemetics was high, $92.8 \%$. A documented $61.9 \%$ of these patients ambulated within 8 hours of surgery, per protocol requirement.

Among patients undergoing open hysterectomy, preemptive analgesia and postoperative analgesia per protocol occurred $66.9 \%$ and $44.4 \%$ of the time, respectively. Compliance with intraoperative and postoperative fluid management was $19.5 \%$ and $57.0 \%$, respectively. Patients undergoing open procedures adhered to the preoperative carbohydrate load at a rate of $40.3 \%$ and used Hibiclens pre-operatively $73.4 \%$ of the time. These patients were less likely to have protocol-based intraoperative antiemetics and timely ambulation, when compared with the patients undergoing minimally invasive hysterectomy, $89.4 \%$ and $12.6 \%$, respectively.

\section{Assessing the Association of ERAS Initiative with LOS}

Figure 2 compares monthly average LOS before and after the intervention by procedure type and table 3 presents results from interrupted time series analysis. Monthly LOS was declining before the initiative started (coef $=-0.43$, $\mathrm{p}=0.008$ ) and the initiative was not associated with significant change in the level (coef $=1.01, \mathrm{p}=0.621)$ or trend $(0.32$. $\mathrm{p}=0.064$ ) in LOS. The Durbin-Watson $d$ test and residual plots indicated no significant autocorrelation in the data.

\section{Assessing the impact of individual ERAS process measures on LOS}

Table 4 shows multivariate regression analysis assessing the impact of individual process measures on LOS.

For minimally invasive procedure, compliance with early mobilisation was associated with reduced LOS). The administration of intraoperative $<4 \mathrm{cc} / \mathrm{kg} / \mathrm{hr}$ ) and postoperative $<1 \mathrm{cc} / \mathrm{kg} /$ hour were associated with increased LOS $(-53 \%, 95 \%$ CI $-52 \%$ to $-55 \%$ and $4 \%, 95 \%$ CI $1 \%$ tpo $7 \%$, respectively). For open procedure, the use of two 

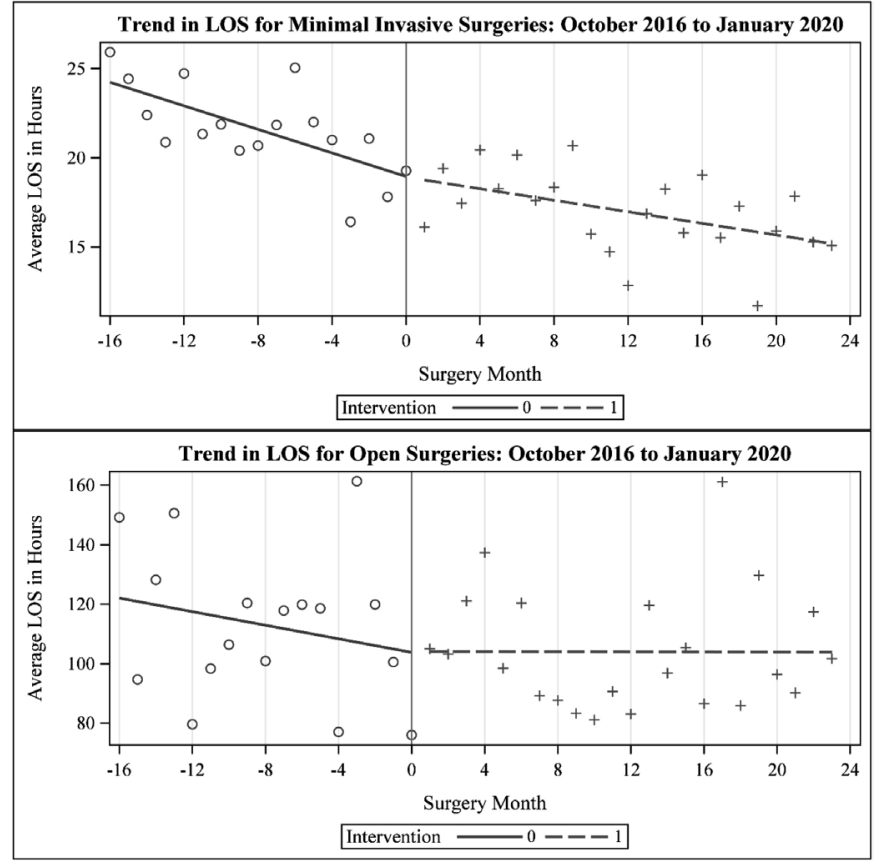

Figure 2 Forest plot presentation of the association of process measures on length of stay (LOS).

or more intraoperative antiemetics $(-30 \%, 95 \%$ CI $-28 \%$ to $-40 \%)$ and postoperative fluid administration of $<1$ $\mathrm{cc} / \mathrm{kg} /$ hour $(-12 \%, 95 \% \mathrm{CI}-1 \%$ to $-21 \%)$ were significantly associated with reduced LOS.

Table 3 Interrupted time series regression results assessing the impact of ERAS on LOS*

\begin{tabular}{lcc}
\hline Covariates & Parameter (SE) & P value \\
\hline Intercept & $23.3(16.9)$ & 0.178 \\
Average age & $-0.03(0.30)$ & 0.909 \\
\hline Per cent open & $0.77(0.11)$ & $<0.001$ \\
\hline Per cent weekend & $0.45(0.22)$ & 0.054 \\
\hline Per cent ASA mild & $-0.04(0.07)$ & 0.556 \\
Per cent ASA missing & $-0.12(0.12)$ & 0.351 \\
Baseline trend & $-0.43(0.15)$ & 0.008 \\
$\begin{array}{l}\text { Level change after } \\
\text { intervention }\end{array}$ & $1.01(2.00)$ & 0.621 \\
$\begin{array}{l}\text { Trend change after } \\
\text { intervention }\end{array}$ & $0.32(0.17)$ & 0.067 \\
\hline Adjusted R-square & 0.71 & \\
\hline
\end{tabular}

*We modelled monthly average LOS as a function of trend (procedure month), intervention period $(0,1)$, and covariates where there was significant difference between the preintervention and postintervention samples (age, ASA rating and weekend). The data had 40 periods (months). ASA, American Society of Anesthesia; ERAS, enhanced recovery after surgery; LOS, length of stay.

\section{DISCUSSION}

Despite the well-studied benefits of ERAS pathways on surgical care, widespread dissemination has remained a challenge due to the sweeping changes it makes in the infrastructure and processes of clinical care. Although some aspects (minimally invasive surgery where possible, limiting tubes, lines and drains) are largely considered standard of care, other measures (preoperative carbohydrate drinks, ambulation within 8 hours after surgery) remain significant departures from routine clinical practices. The majority of the literature has described ERAS implementation in an intention-to-treat analysis, assuming total compliance. However, more recent literature shows that institutions have marked difficulty in adherence to the bundle, particularly over time. ${ }^{13-18} 2728$ These challenges, and a resource limited environment, make it important to investigate which measures are the most critical to achieving improved outcomes.

In our study, we analysed the association of ten ERAS metrics which would not be considered widespread surgical standard of care on LOS. We found that the association on LOS varied by measure, and in particular, by surgical approach. Rigid control of intraoperative and postoperative fluids was associated with increased LOS in minimally invasive cases but appeared to have the opposite association for open procedures. The increase in LOS noted in minimally invasive procedures may be confounded by the fact that most patients undergoing vaginal/laparoscopic hysterectomy are discharged day of surgery (median LOS of 12 hours), and as such patients that are admitted and administered fluids represents a cohort requiring more medical management or monitoring based on the surgical teams' assessment of the patients' comorbidities and risk for complications. Consistent with our results, in the international validation of ERAS society guidelines in gynaecological surgery, the authors also demonstrated the finding that the more complex the surgery, the more LOS was reduced by administering 'balanced' intravenous fluids. ${ }^{29}$ Our study supports the importance of two or more antiemetics in gynaecological patients, a group well recognised to be at high risk for postoperative nausea and vomiting. Finally, we found that early postoperative ambulation was (1) difficult to implement (compliant in only $12.6 \%$ of debulking surgery) and (2) significantly associated with decreasing LOS, with an $18 \%$ reduction in LOS for open cases.

Several other investigators have evaluated the effect size we report in our study and have similarly attributed it to route of hysterectomy and how LOS is measured. ${ }^{30-33} \mathrm{In}$ a case-control study of vaginal hysterectomy, the authors found ERAS implementation was associated with reduction of 23.5 hours in LOS (LOS was measured in hours). ${ }^{30}$ In a randomised clinical trial, the authors reported that ERAS reduced LOS in patients undergoing open hysterectomy by 1.18 days (95\% CI -1.5767 to -0.7833 ) and for patients undergoing laparoscopic hysterectomy by 0.42 days $(95 \%$ CI -0.744 to -0.096$) .{ }^{31}$ Another study documented ERAS to be associated with 0.3 days reduction 
Table 4 Multivariate regression results assessing association of individual process metrics and LOS

\begin{tabular}{|c|c|c|c|c|}
\hline \multirow[b]{2}{*}{ Covariates } & \multicolumn{2}{|c|}{ Minimally invasive surgery } & \multicolumn{2}{|c|}{ Open surgery } \\
\hline & Rate ratio & $95 \% \mathrm{Cl}$ & Rate ratio & $95 \% \mathrm{Cl}$ \\
\hline \multicolumn{5}{|l|}{ Age group (ref $\leq 45$ ) } \\
\hline $46-65$ years & 1.03 & 1.00 to 1.07 & 1.15 & 1.01 to 1.31 \\
\hline$>65$ years & 1.09 & 1.05 to 1.13 & 1.29 & 1.11 to 1.50 \\
\hline \multicolumn{5}{|l|}{ BMI (ref=normal) } \\
\hline Overweight & 1.05 & 1.01 to 1.08 & 1.07 & 0.95 to 1.21 \\
\hline Obese & 0.97 & 0.94 to 1.01 & 1.18 & 1.04 to 1.33 \\
\hline \multicolumn{5}{|l|}{ ASA (ref=mild) } \\
\hline Healthy & 0.97 & 0.92 to 1.02 & 0.90 & 0.67 to 1.12 \\
\hline Severe & 1.07 & 1.02 to 1.11 & 1.12 & 0.97 to 1.29 \\
\hline Missing & 0.97 & 0.93 to 1.02 & 1.13 & 0.99 to 1.27 \\
\hline Has diabetic & 1.03 & 0.98 to 1.08 & 0.99 & 0.82 to 1.20 \\
\hline Weekend (ref=weekdays) & 1.12 & 1.03 to 1.23 & 1.08 & 0.90 to 1.29 \\
\hline \multicolumn{5}{|l|}{ Surgery year ${ }^{*}(r e f=2017)$} \\
\hline 2018 & 0.96 & 0.92 to 1.00 & 0.90 & 0.78 to 1.03 \\
\hline 2019 & 0.90 & 0.87 to 0.94 & 0.91 & 0.79 to 1.05 \\
\hline \multicolumn{5}{|l|}{ Process metrics } \\
\hline Preemptive analgesia & 1.00 & 0.97 to 1.03 & 1.09 & 0.98 to 1.21 \\
\hline Intraop $<4 \mathrm{cc} / \mathrm{kg} / \mathrm{hour}$ & 1.04 & 1.01 to 1.07 & 0.91 & 0.80 to 1.04 \\
\hline Antiemetics & 1.03 & 0.97 to 1.08 & 0.70 & 0.60 to 0.82 \\
\hline Postop analgesia & 1.01 & 0.98 to 1.04 & 1.01 & 0.91 to 1.11 \\
\hline Postop $<1 \mathrm{cc} / \mathrm{kg} /$ hour & 1.37 & 1.32 to 1.42 & 0.88 & 0.79 to 0.99 \\
\hline Ambulation $<8$ hours & 0.47 & 0.45 to 0.48 & 0.92 & 0.79 to 1.07 \\
\hline Bowel preparation & NA & & 1.13 & 1.00 to 1.27 \\
\hline Preoperative carbohydrate drink & 1.00 & 0.96 to 1.04 & 1.08 & 0.97 to 1.21 \\
\hline Preoperative chlorhexidine wash & 1.00 & 0.97 to 1.03 & 0.92 & 0.81 to 1.03 \\
\hline Likelihood ratio test $\dagger$ & \multicolumn{2}{|c|}{$\chi^{2}(20)=2419, p<0.001$} & \multicolumn{2}{|c|}{$\chi^{2}(21)=84, p<0.001$} \\
\hline
\end{tabular}

${ }^{*}$ For surgery year, data from October to December 2016 data are treated as 2017 data and January 2020 data are treated as 2019 data.

$\dagger$ The likelihood ratio test compares an empty model with the model specified in the table.

ASA, American Society of Anesthesia; BMI, body mass index; LOS, length of stay; NA, not availble.

in LOS among patients undergoing hysterectomy by laparotomy route (2.6 days before ERAS vs 2.3 days after ERAS, $\mathrm{p}=0.011) .{ }^{32}$ In a study defining LOS as a binary outcome, discharged home after surgery or admitted to hospital, ERAS implementation reduced admission to the hospital after surgery by $40 \%$ ( $70 \%$ before vs $33 \%$ after ERAS implementation, $\mathrm{p}<0.05){ }^{33}$

The results of our study underscore the importance of measuring strict adherence to ERAS pathways bundle items in order to optimise programme success. It also highlights the benefit of tailoring the protocol to include only critical items that will facilitate programme implementation, adherence and sustainability. As surgical innovation and efforts to improve value-based care delivery evolve, continued research in identifying key and relevant ERAS pathway components will be necessary in order to facilitate and identify opportunities to complement other care programmes such as home hospital services.

Strengths of our study include that ERAS was implemented by a robust centralised team with high fidelity data capture and strict criteria for compliance. All surgeons, without exclusion, participated in ERAS. Data were captured prospectively, and our large volume of surgeries allowed us to differentiate the associations of the process measures on both minimally invasive versus open surgeries. The study also has several limitations. Our results are based on observational data and we cannot claim the observed relationship between LOS and ERAS measures reflect causal relationship. Other limitations include relatively low compliance in certain measures, and inability to further analyse debulking/open procedures based on surgical radicality. 
In summary, our study results show that overall compliance with the bundle is critical to achieving all the benefits of ERAS including shortened LOS and reduced perioperative complications. Importantly, our study provides additional specific guidance, including an abbreviated ERAS bundle, for centres particularly interested in ERAS measures more likely associated with reduction in LOS. For these institutions, quality improvement projects should focus particularly on both fluid administration and early ambulation in open hysterectomy procedures.

Contributors All authors contributed to the study design, data collection, data analysis, manuscript preparation, review and revision.

Funding The authors have not declared a specific grant for this research from any funding agency in the public, commercial or not-for-profit sectors.

Competing interests None declared.

Patient consent for publication Not required.

Ethics approval This study was approved by our Healthcare Institutional Review Board (Protocol number: 2017P000443). The institutional review board at Massachusetts General Hospital approved this study; informed consent was waived given the quality improvement nature of the project.

Provenance and peer review Not commissioned; externally peer reviewed.

Data availability statement Data are available on reasonable request. Dissemination to participants and related patient and public communities: We do not plan any participant dissemination as there were no public member or patient participant involvement. We will widely disseminate the results of this study to professional colleagues and to the public, through conference and meeting presentations and media reporting.

Open access This is an open access article distributed in accordance with the Creative Commons Attribution Non Commercial (CC BY-NC 4.0) license, which permits others to distribute, remix, adapt, build upon this work non-commercially, and license their derivative works on different terms, provided the original work is properly cited, appropriate credit is given, any changes made indicated, and the use is non-commercial. See: http://creativecommons.org/licenses/by-nc/4.0/.

ORCID iD

Marcela G. del Carmen http://orcid.org/0000-0002-3102-692X

\section{REFERENCES}

1 Ljungqvist $\mathrm{O}$, Scott M, Fearon KC. Enhanced recovery after surgery: a review. JAMA Surg 2017;152:292-8.

2 Fearon KCH, Ljungqvist O, Von Meyenfeldt M, et al. Enhanced recovery after surgery: a consensus review of clinical care for patients undergoing colonic resection. Clin Nutr 2005;24:466-7.

3 Bardram L, Funch-Jensen P, Jensen P, et al. Recovery after laparoscopic colonic surgery with epidural analgesia, and early oral nutrition and mobilisation. Lancet 1995;345:763-4.

4 Greco M, Capretti G, Beretta L, et al. Enhanced recovery program in colorectal surgery: a meta-analysis of randomized controlled trials. World J Surg 2014;38:1531-41.

5 Zhao $\mathrm{Y}$, Qin H, Wu Y, et al. Enhanced recovery after surgery program reduces length of hospital stay and complications in liver resection: a PRISMA-compliant systematic review and meta-analysis of randomized controlled trials. Medicine 2017;96:e7628.

6 Yang R, Tao W, Chen Y-Y, et al. Enhanced recovery after surgery programs versus traditional perioperative care in laparoscopic hepatectomy: a meta-analysis. Int J Surg 2016;36:274-82.

7 Xiong J, Szatmary P, Huang W, et al. Enhanced recovery after surgery program in patients undergoing pancreaticoduodenectomy: a PRISMA-Compliant systematic review and meta-analysis. Medicine 2016;95:e3497.

8 Kalogera E, Bakkum-Gamez JN, Jankowski CJ, et al. Enhanced recovery in gynecologic surgery. Obstet Gynecol 2013;122:319-28.

9 Miralpeix E, Nick AM, Meyer LA, et al. A call for new standard of care in perioperative gynecologic oncology practice: impact of enhanced recovery after surgery (ERAS) programs. Gynecol Oncol 2016;141:371-8.
10 Modesitt SC, Sarosiek BM, Trowbridge ER, et al. Enhanced recovery implementation in major gynecologic surgeries: effect of care standardization. Obstet Gynecol 2016;128:457-66.

11 Wijk L, Franzén $\mathrm{K}$, Ljungqvist $\mathrm{O}$, et al. Enhanced recovery after surgery protocol in abdominal hysterectomies for malignant versus benign disease. Gynecol Obstet Invest 2016;81:461-7.

$12 \mathrm{Hu}$ Z-C, He L-J, Chen D, et al. An enhanced recovery after surgery program in orthopedic surgery: a systematic review and metaanalysis. J Orthop Surg Res 2019;14:77.

13 Gotlib Conn L, McKenzie M, Pearsall EA, et al. Successful implementation of an enhanced recovery after surgery programme for elective colorectal surgery: a process evaluation of champions' experiences. Implement Sci 2015;10:99.

14 Ament SMC, Gillissen F, Moser A, et al. Identification of promising strategies to sustain improvements in hospital practice: a qualitative case study. BMC Health Serv Res 2014;14:641.

15 Cohen R, Gooberman-Hill R. Staff experiences of enhanced recovery after surgery: systematic review of qualitative studies. BMJ Open 2019;9:e022259.

16 Gustafsson UO, Hausel J, Thorell A. Adherence to the enhanced recovery after surgery protocol and outcomes after colorectal cancer surgery. Arch Surg 2011;146:571-7.

17 ERAS Compliance Group. The impact of enhanced recovery protoco compliance on elective colorectal cancer resection: results from an international registry. Ann Surg 2015;261:1153-9.

18 Gillissen F, Ament SMC, Maessen JMC, et al. Sustainability of an enhanced recovery after surgery program (ERAS) in colonic surgery. World J Surg 2015;39:526-33.

19 Damschroder LJ, Aron DC, Keith RE, et al. Fostering implementation of health services research findings into practice: a consolidated framework for advancing implementation science. Implement Sci 2009;4:50.

20 Nelson G, Altman AD, Nick A, et al. Guidelines for pre- and intraoperative care in gynecologic/oncology surgery: Enhanced Recovery After Surgery (ERAS $\otimes)$ Society recommendations--Part I. Gynecol Oncol 2016;140:313-22.

21 Nelson G, Altman AD, Nick A, et al. Guidelines for postoperative care in gynecologic/oncology surgery: Enhanced Recovery After Surgery (ERAS $\otimes$ ) Society recommendations--Part II. Gynecol Oncol 2016;140:323-32.

22 Chapman JS, Roddy E, Ueda S, et al. Enhanced recovery pathways for improving outcomes after minimally invasive gynecologic oncology surgery. Obstet Gynecol 2016;128:138-44.

23 Kalogera E, Dowdy SC. Enhanced recovery pathway in gynecologic surgery: improving outcomes through evidence-based medicine. Obstet Gynecol Clin North Am 2016;43:551-73.

24 Gatt M, Anderson ADG, Reddy BS, et al. Randomized clinical trial of multimodal optimization of surgical care in patients undergoing major colonic resection. Br J Surg 2005;92:1354-62.

25 Ban KA, Minei JP, Laronga C, et al. American College of surgeons and surgical infection Society: surgical site infection guidelines, 2016 update. J Am Coll Surg 2017;224:59-74.

26 Migaly J, Bafford AC, Francone TD, et al. The American Society of colon and rectal surgeons clinical practice guidelines for the use of bowel preparation in elective colon and rectal surgery. Dis Colon Rectum 2019;62:3.

27 Pearsall EA, Meghji Z, Pitzul KB, et al. A qualitative study to understand the barriers and enablers in implementing an enhanced recovery after surgery program. Ann Surg 2015;261:92-6.

28 Paton F, Chambers D, Wilson P, et al. Effectiveness and implementation of enhanced recovery after surgery programmes: a rapid evidence synthesis. BMJ Open 2014;4:e005015.

29 Wijk L, Udumyan R, Pache B, et al. International validation of enhanced recovery after surgery Society guidelines on enhanced recovery for gynecologic surgery. Am J Obstet Gynecol 2019;221:237e1.

30 Yoong W, Sivashanmugarajan V, Relph S, et al. Can enhanced recovery pathways improve outcomes of vaginal hysterectomy? cohort control study. J Minim Invasive Gynecol 2014;21:83-9.

31 Abdelrazik AN, Sanad AS. Implementation of enhanced recovery after surgery in gynecological operations: a randomized controlled trial. Ain-Shams J Anesthesiol 2020;12.

32 Wijk L, Franzen K, Ljungqvist O, et al. Implementing a structured enhanced recovery after surgery (ERAS) protocol reduces length of stay after abdominal hysterectomy. Acta Obstet Gynecol Scand 2014;93:749-56.

33 Huang J, Vaught J, Meir L. Reduced length of hospital stay in laparoscopic hysterectomy after implementation of enhanced recovery after surgery (ERAS) protocol: a pilot program result. Trans/ Perioper Pain Med 2017;4:18-23. 